\title{
PRAEFATIO EDITORIS.
}

$\mathbf{H}$ AnPocratronem codices alii talem fere habent qualem cum lexico Segueriano sexto Endemus Photius Suidas, alii talem qualis vulgo clitur. illins ego generis nsus sum duobus, D et E, huius derem, ABCFGHIKLM. est antem

A Angelicanns C 4 17, olim Passionens et SSylvestris, forma quadrata, foliis 98, chartacens.

B Vaticanus 1362, ex libris Fulvii Ursini, forma maxima, chartaceus; cui inest post Harpocrationem (f. 1-70) $\tau \hat{\tilde{z}}$

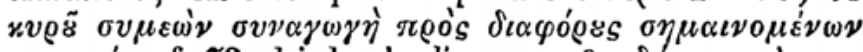
$\sigma \eta \mu c s \sigma i \alpha s$ f. 73, leinde, ab alia mann $\vartheta \varepsilon o \delta \omega \rho s, \pi \varepsilon \rho i, \mu \eta-$

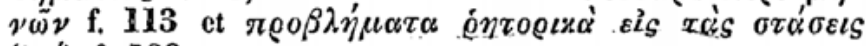

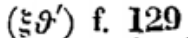

G Yratislaviensis gymnasii Magdalenei, de quo Passovins Symbol. erit. e mss. Yrat. p. 32.

D Parisiensis nunc Regius 2552, olim Colhertinus 4898, chartacens, quadratus minimi moduli. is Harpocrationi subiicit

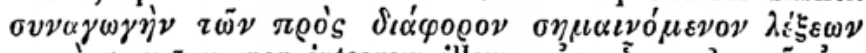

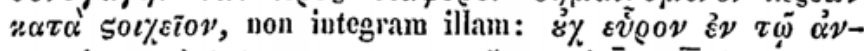
$\tau \iota \gamma \varrho \alpha$ '

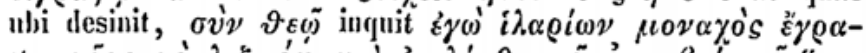

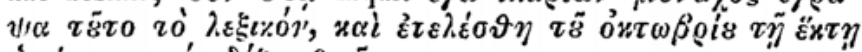

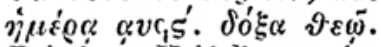

E Palatinus Heidelbergensis 375, forma maxima, membrauacens, omnimm antiquissimus: (f. Kühn. Polluc. praefit. p. 10 a.

F Lanrentianus 55 14, forma maxima, foliis 262, membranacens. Harpocrationem anteit (f. $1-43$ ) Theolorns de men-

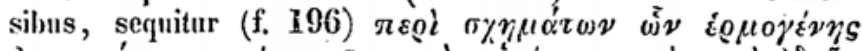

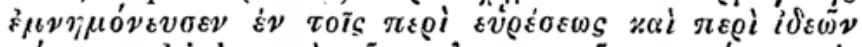

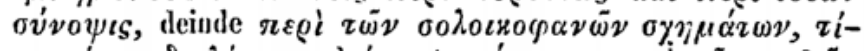

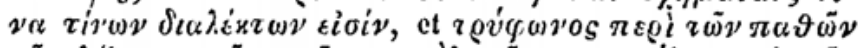

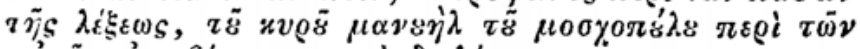

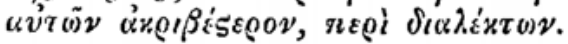


G Lanrentianus 58 \&, forma maxima, folis $\mathbf{1 2 0}$, chartacens,

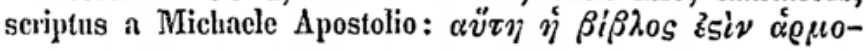

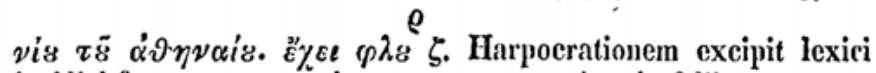
iuridici fragmentum, scriptum manu recentiore in foliis sex mem-

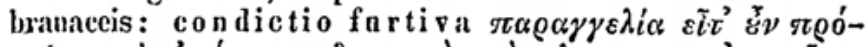

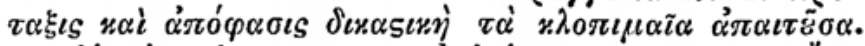
condictio ob turpem vel iniustam causam

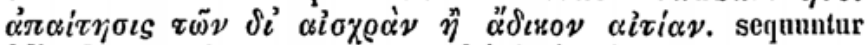
folia duo membranacea vacua: deinde in charta, ab Aposto-

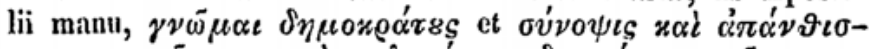

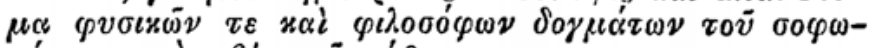

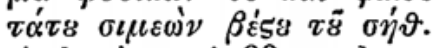

H Ambrosianus A 99, quadratus, membranaceus.

1 Marcianus 443, forma maxima, foliis 82 , chartaceus, Bessarionens, non distinctis ant glossis aut litteris.

K Marcianus 444, quadratus, foliis 343, manuum plurimm opus, quarum antiquissima scripsit Harpocrationis p. $\mathbf{1}-44 \mathbf{1 1}$,

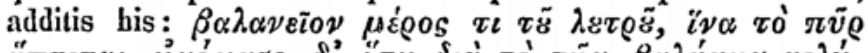

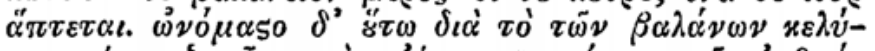

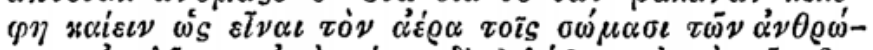

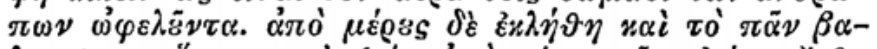

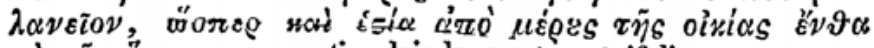
тò $\pi \tilde{v} \varrho \ddot{c} \pi \tau \varepsilon \tau \alpha \iota$. recentior deinde, post sesqnifotium vacunm, $\mathrm{p}$. 4412 - 180 6, ceterae Pindarm, Michaclis Syncelli sya-

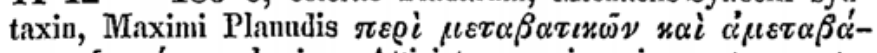
$\tau \omega \nu$ $\eta \mu \alpha^{\prime} \tau \omega \nu$, lexicon Atticistae nescio cuius, atque antea Aphthonium et Hermogenem.

L Marcianus 490 , forma maxima, foliis $\mathbf{1 4 7}$, chartacens. Harpocrationem (inde a f. 132) non ultra p. 59 habet.

M Palatinus Vaticanus 87l.

his addere visum, quos Werferns et Maussacus iuspexere,

N Darmstadiensem (Act. Monac. 3 p. 237) et

0 .Morcllianum ac Vaticanum.

meornm totos comparavi $A B C$, ceterorum particulas, velut ex FM litteram sminpsi $\alpha$, ex G $\sigma$, ex I $\delta$, ex $\mathbf{L} \beta \gamma$, ex E p. $1-74$ 18, ex H p. $\mathrm{I}-129$, ex K p. 1 - 13 18. D ita excerpsi nt, quae omitteret, non cominemorarem. G ubi extra $\sigma$ adyocatur, fide advocatur Gronovii.

Moermis expressi, qui unus mihi superesse villetur; codicem Coislinianm 3 노.

Scrib. Berolini Cal. Sept. a. 1833. 